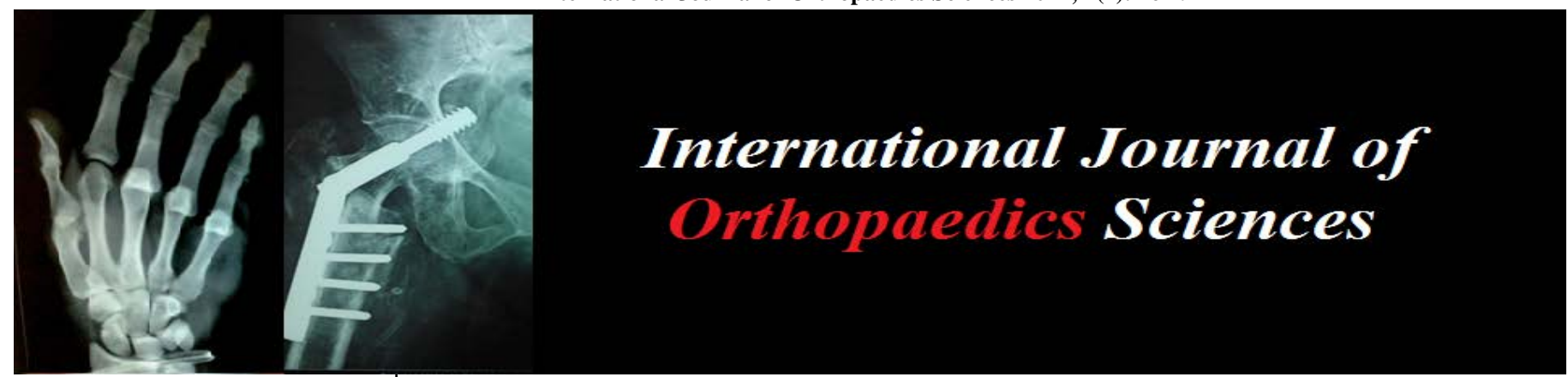

E-ISSN: 2395-1958

P-ISSN: 2706-6630

IJOS 2021; 7(4): 26-29

(C) 2021 IJOS

www.orthopaper.com

Received: 04-08-2021

Accepted: 11-09-2021

Dr. Pradeep Choudhari Professor and Head of

Department, Department of Orthopaedics, Sri Aurobindo

Medical College \& P.G. Institute

Indore, Madhya Pradesh, India

Dr. Utkarsh Goyal

Senior Resident, Department of

Orthopaedics, Sri Aurobindo

Medical College \& P.G. Institute

Indore, Madhya Pradesh, India

Dr. Bikramdeep Singh

Post Graduate, Department of

Orthopaedics, Sri Aurobindo

Medical College \& P.G. Institute

Indore, Madhya Pradesh, India

Corresponding Author:

Dr. Pradeep Choudhari

Professor and Head of

Department, Department of

Orthopaedics, Sri Aurobindo

Medical College \& P.G. Institute

Indore, Madhya Pradesh, India

\section{Functional outcome of early movement of knee in transverse patellar fractures treated by modified tension band wiring}

\author{
Dr. Pradeep Choudhari, Dr. Utkarsh Goyal and Dr. Bikramdeep Singh
}

DOI: https://doi.org/10.22271/ortho.2021.v7.i4a.2861

\section{Abstract}

Background: The patella is the biggest sesamoid bone of the human frame located in front of the knee. Patellar fracture account for about one percent of all fractures and are most common within the age group of 20-50 years. Modified tension band wiring is the excellent for displaced transverse fractures. The principle of TBW is that tension forces at fracture site are converted to compression force.

Materials and Method: This is a prospective study. This study was carried out at Sri aurobindo medical college and Pg institute during the period of January 2020 to May 2021. The functional status of the knee was analyse. Open reduction and internal fixation of the fractures were done by modified tension band wiring within 1 week of fracture.

Result: The mean age of the patients was $33.70 \pm 6.73$ years with a range from 23 to 49 years. There were $8(40 \%)$ females and $12(60 \%)$ males i, showing a male predominance. In $8(40 \%)$ patients sustained injury due to fall and in $12(60 \%)$ patients sustained injury due to road traffic accident. Conclusion: The modified tension band wiring is simple with a short period of learning curve, safe, inexpensive and effective technique in transverse fracture of patella because of good stability of implant, early joint mobilization with minimum complications and with easier post-operative rehabilitation.

Keywords: Tension band wiring, transverse patellar fracture, functional outcome.

\section{Introduction}

The patella is the biggest sesamoid bone of the human frame located in front of the knee and is embedded within the quadriceps tendon ${ }^{[1]}$. It is one of the few bones without a periosteal coverage. The proximal three-fourths of the patella are covered through a thick layer of cartilage, while the ultimate distal pole is not part of the articular congruency. The adjoining quadriceps muscle include four muscles tissue, of which the rectus femoris is the longest and maximum superficial. Patella fractures is an intra-articular fracture involving the patella femoral joint. Patellar fracture account for about one percent of all fractures and are most common within the age group of 20-50 years. Epidemiologic studies proven that the prevalence in men is twice as high as in women. Fracture patella can arise both through direct or oblique force. As an end result of the bony lesion the extensor mechanism of the knee joint can emerge as insufficient. Transverse fracture of patella is usually because of violent contraction of quadriceps muscle tissue with knee flexion. There are numerous varieties of surgical remedy for fracture patella. They are open reduction and internal fixation with inter fragmentary screws, tension band wiring, circlage wiring, combined tension band wiring and circlage wiring, partial patellectomy, total patellectomy. Modified tension band wiring is the excellent remedy for displaced transverse fractures. The principle of TBW is that tension forces at fracture site are converted to compression force ${ }^{[2] .}$

\section{Materials and Method}

This is a prospective study. This study was carried out at Sri aurobindo institute of medical sciences and Pg institute during the period of JANUARY 2020 to MAY 2021. The patients for the study were selected on random basis after fulfilling the following criteria: 


\section{Inclusion criteria}

1. Displaced Transverse fractures.

2. Closed fracture.

3. Presented within three weeks of injury.

4. Adult ( $>18$ years)

\section{Exclusion criteria}

1. Age less than 18 years.

2. Open fractures

3. Patient not giving consent of surgery.

20 patients $(n=20)$ with displaced transverse fracture were included in this study. Subjective and objective evaluations of all patients were carried out postoperatively for about 12 months. In this study results obtained to compare the functional status of the knee were analyse. Open reduction and internal fixation of the fractures were done by modified tension band wiring within 1week of fracture. Post operatively when pain was within tolerable limit (within 24 to 48 hrs) assisted active movement of knee and isometric quadriceps exercise were started. The patients were allowed to walk with crutch (non- weight bearing) within first week and gradual weight bearing started after 2 weeks. All patients were taught static quadriceps strengthening exercises The patients were followed up at the end of 3rd, 6th, 12th, 24th and 52nd weeks. Every time the functional status of knee was assessed using knee society score and check x-rays was done at regular intervals to assess fracture union and looked for any complications.

\section{Operative Technique}

In the surgery, open reduction and internal fixation with modified tension band wiring was done. Standard strategy was followed. 2- Kirschner wires of $2 \mathrm{~mm}$ each were passed through the fracture site into proximal fragment in an outside in technique. On the coronal view the $2 \mathrm{k}$ wires are placed parallel to each other along two lines which divided patella into Medial, central and Lateral thirds and on sagittal view $2 \mathrm{k}$ wires were placed closed to the articular surface than to the anterior surface of the patella. The $\mathrm{k}$ wires were driven until they were flushed to the fracture site. With the knee in a slightly flexed position the fracture was reduced using patellar reduction clamp [3]. Absolute care was taken to achieve accurate articular congruity in anatomical position and then the wires were driven through the distal fragments. Wire ends were kept long enough, to protrude beyond patella, both superiorly and inferiorly. Then the $1 \mathrm{~mm}$ thick stainless steel wire was passed transversely through the quadriceps tendon attachment as close as possible to the bone throughout its whole course both superiorly and inferiorly. Then figure of 8 loop was made on anterior surface of reduced patella, by transversely passing the wire through patellar tendon attachment on inferior fragment again close to the bone and deep to the protruding $\mathrm{K}$ wire. The loop wire was tightened with tensioner, and then twisted and cut short. Articular surface of patella was again checked for articular congruity. Upper ends of the two $\mathrm{K}$ wires were bent acutely and cut short. The proximal cut ends were turned 180 degrees towards the quadriceps tendon and were driven into the patella posterior to the wire loop. The distal pin ends are trimmed to remove the sharp points,but are not bent, for easier removal. Retinacular tears were sutured. Skin closed in layers with suction drain in situ. Wound was dressed and tourniquet was released. Static and isometric exercises within the limit of pain were also encouraged from second or third post op day. The patient was discharged on the 14th post-operative day after suture removal. We had advised for removal of hardware after about 1 year and earlier if patient had any symptom.
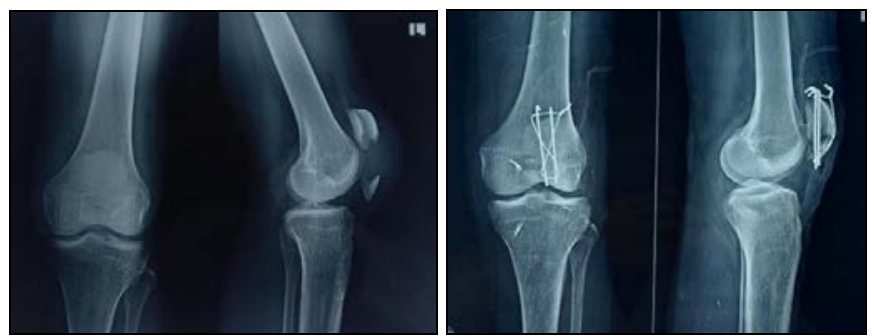

Fig 1: Showing pre-operative and post-operative X-rays

\section{Results}

Table 1: Distribution of patients according to age

\begin{tabular}{|c|c|c|}
\hline Age & Number & Percentage \\
\hline 23-30 years & 7 & 35.0 \\
\hline 31-40 years & 10 & 50.0 \\
\hline 41-50 years & 3 & 15.0 \\
\hline Total & 20 & 100.0 \\
\hline
\end{tabular}

7 (35\%) patients were in the age group 23-30 years, 10 (50\%) were in the age group 31-40 years and 3 (15\%) were in the age group 41-50 years.

Majority of the patients were in the age group 31-40 years. The mean age of the patients was $33.70 \pm 6.73$ years with a range from 23 to 49 years.

Table 2: Distribution according to sex

\begin{tabular}{|c|c|c|}
\hline Sex & Number & Percentage \\
\hline Female & 8 & 40.0 \\
\hline Male & 12 & 60.0 \\
\hline Total & 20 & 100.0 \\
\hline
\end{tabular}

There were 8 (40\%) females and 12 (60\%) males in our study, showing a male predominance.

Table 3: Distribution according to side involved

\begin{tabular}{|c|c|c|}
\hline Side involved & Number & Percentage \\
\hline Left side & 8 & 40.0 \\
\hline Right side & 12 & 60.0 \\
\hline Total & 20 & 100.0 \\
\hline
\end{tabular}

In 8 (40\%) patients had left side involvement and 12 (60\%) patients had right sided involvement. Majority of the patients had right side involvement.

Table 4: Distribution according to mode of injury

\begin{tabular}{|c|c|c|}
\hline Mode of Injury & Number & Percentage \\
\hline Fall & 8 & 40.0 \\
\hline Road Traffic Accident & 12 & 60.0 \\
\hline Total & 20 & 100.0 \\
\hline
\end{tabular}

In $8(40 \%)$ patients sustained injury due to fall and in 12 (60\%) patients sustained injury due to road traffic accident. Majority of the patients sustained injury due to road traffic accident. 
Table 5: Time interval between trauma and surgery (days)

\begin{tabular}{|c|c|c|}
\hline $\begin{array}{c}\text { Time Interval between Trauma and } \\
\text { Surgery (Days) }\end{array}$ & Number & Percentage \\
\hline 1 day & 6 & 30.0 \\
\hline 2 days & 9 & 45.0 \\
\hline 3 days & 5 & 25.0 \\
\hline Total & 20 & 100.0 \\
\hline
\end{tabular}

In 6 (30\%) patients the time interval between trauma and surgery was 1 day, in 9 (45\%) patients it was 2 days and in 5 (25\%) patients it was 3 days.

In majority of the patients the time interval between trauma and surgery was 2 days.

The mean time interval between trauma and surgery was 1.95 \pm 0.76 days with a range between 1 to 3 days.

Table 6: Comparison of KSS at different time intervals

\begin{tabular}{|c|c|c|c|c|}
\hline Time Interval & No. & Mean \pm SD & 't' value & P value \\
\hline 3 weeks & 20 & $47.15 \pm 3.49$ & \multirow{2}{*}{$-12.259, \mathrm{df}=19$} & \multirow{2}{*}{$0.001^{*}$} \\
\hline 6 weeks & 20 & $63.75 \pm 5.36$ & & \\
\hline 6 weeks & 20 & $63.75 \pm 5.36$ & \multirow{2}{*}{$-6.088, \mathrm{df}=19$} & \multirow{2}{*}{$0.001^{*}$} \\
\hline 12 weeks & 20 & $=7.15$ & & \\
\hline 12 weeks & 20 & $72.00 \pm 7.15$ & \multirow{2}{*}{$-9.372, \mathrm{df}=19$} & \multirow{2}{*}{$0.001 *$} \\
\hline 24 weeks & 20 & $81.30 \pm 7.92$ & & \\
\hline 24 weeks & 20 & $81.30 \pm 7.92$ & \multirow{2}{*}{$-9.319, \mathrm{df}=19$} & \multirow{2}{*}{$0.001^{*}$} \\
\hline 52 weeks & 20 & $92.55 \pm 10.22$ & & \\
\hline
\end{tabular}

Paired ' $t$ ' test applied. $P$ value $<0.05$ was taken as statistically significant

The mean KSS score at 3 weeks was $47.15 \pm 3.49$, at 6 weeks it was $63.75 \pm 5.36$, at 12 weeks it was $72.00 \pm 7.15$, at 24 weeks it was $81.30 \pm 7.92$ and at 52 weeks it was $92.55 \pm$ 10.22 .

There was a significant improvement in mean KSS score at 6 weeks in comparison to 3 weeks $(\mathrm{P}=0.001)$, at 12 weeks in comparison to 6 weeks ( $\mathrm{P}=0.001)$, at 24 weeks in comparison to 12 weeks $(\mathrm{P}=0.001)$ and at 52 weeks in comparison to 24 weeks $(\mathrm{P}=0.001)$.

There is a significant improvement from 6 weeks till 52 weeks in the mean KSS score.

Table 7: Distribution according to complications

\begin{tabular}{|c|c|c|}
\hline Complications & Number & Percentage \\
\hline None & 18 & 90.0 \\
\hline Non-union & 1 & 5.0 \\
\hline Superficial wound infection & 1 & 5.0 \\
\hline Total & 20 & 100.0 \\
\hline
\end{tabular}

In 1 (5\%) patient there was non-union and 1 (5\%) patient had superficial wound infection. In 18 (90\%) patients had no complications.

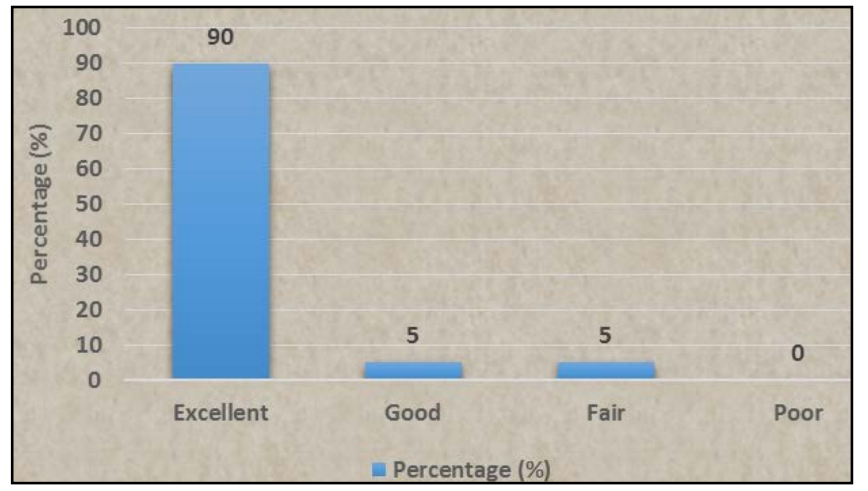

Graph 1: Bar diagram showing final outcome at 52 weeks
At 52 weeks, 18 (90\%) patients had excellent outcome, 1 (5\%) patient had fair outcome and 1 (5\%) patient had fair outcome.

\section{Discussion}

Modified tension band wiring is commonly used method to treat transverse patellar fracture. In this study, open reduction and internal fixation was done by modified tension band wiring. Early knee movement was initiated in all the cases post operatively along with other physiotherapy measure. In this study out of the 20 patients ,7 (35\%) patients were in the age group 23-30 years, 10 (50\%) were in the age group 31-40 years and $3(15 \%)$ were in the age group $41-50$ years. The mean age of the patients was $33.70 \pm 6.73$ years with a range from 23 to 49 years. Levack B et al. conducted study on patellar fracture and observed 49 years was average age for patellar fracture ${ }^{[4]}$. There were 8 (40\%) females and 12 (60\%) males in our study, which shows a male predominance. Similar pattern of results was observed in study conducted by Maini PS et al ${ }^{[5]}$. Males active participation in daily activities make them more exposed to trauma. In our study 8 (40\%) patients had left side involvement and 12 (60\%) patients had right sided involvement comparable to Hanumantharaya GH study Right knee was involved in 20 (62.5\%) cases, while the left knee involved in $12(37.5 \%)$ cases. It may be due to the fact that the right dominant side makes vulnerable for trauma. In our study $8(40 \%)$ patients sustained injury due to fall and in $12(60 \%)$ patients sustained injury due to road traffic accident comparable to Pandit and Shah study mechanism of trauma was $80 \%$ due to indirect trauma and $20 \%$ due to direct trauma. In 6 (30\%) patients the time interval between trauma and surgery was 1 day, in 9 (45\%) patients it was 2 days and in $5(25 \%)$ patients it was 3 days. The mean time interval between trauma and surgery was $1.95 \pm 0.76$ days with a range between 1 to 3 days comparable to study by M.B. Gupta where $71.43 \%$ patients were operated within 72 hours of injury while $14.85 \%$ patients were operated between 72 hours to 1 week after injury and $14.85 \%$ patients were operated 1 week after Injury. The mean KSS score at 3 weeks was $47.15 \pm 3.49$, at 6 weeks it was $63.75 \pm 5.36$, at 12 weeks it was $72.00 \pm 7.15$, at 24 weeks it was $81.30 \pm 7.92$ and at 52 weeks it was $92.55 \pm 10.22$. There is a significant improvement from 6 weeks till 52 weeks in the mean KSS score. In our study all patients had radiological union at 812th week but in 1 (5\%) patient there was non-union and 1 (5\%) patient had superficial wound infection which was treated by antibiotics comparable to Peterson KK ${ }^{\text {[6] }}$ et al which found 4 cases of infection out of 45 operated patellar fracture. At 52 weeks, 18 (90\%) patients had excellent outcome, 1 (5\%) patient had fair outcome and 1 (5\%) patient had fair outcome as comparable to study by Tarek et al ${ }^{[7]}$ in his study of 30 patients showed knee society score excellent in $75 \%$ patients good in $20 \%$ patients and fair in 05 patients out of 30 patients. The tension band wiring for transverse fractures of patella yields good results as evident in this study.

\section{Conclusion}

By observing and comparing the results of our study it was concluded that:

The modified tension band wiring is simple with a short period of learning curve, safe, inexpensive and effective technique in transverse fracture of patella because of good stability of implant, early joint mobilization with minimum complications and with easier post-operative rehabilitation. This technique may have some drawbacks as second 
procedure is needed for removal of the metallic implant and risk of K-wire sliding and causing skin problems. However application of tension band principle in operative management of fracture patella has gained great popularity thus enabling the patient to smoothly resume his work without hampering his day-to-day life.

\section{References}

1. Hanumantharaya GH. Functional outcome with modified tension band wiring for patella fractures. Int J Orthop Sci 2017;3(2):455-457.

2. Aggarwal Sumit, Raghuwanshi, et al. Outcome study of application of modified tension band wiring (TBW) in patellar fracture: GJRA - Global Journal for Research Analysis. 4. 100-103.

3. Vishal Singh et al International Journal of Research in Orthopaedics Singh $\mathrm{V}$ et al. Int $\mathrm{J}$ Res Orthop 2021;7(2):351-356.

4. Levack B, Flannagan JP, Hobbs S. Results of surgical treatment of patellar fractures. J Bone Joint Surg $\mathrm{Br}$ 1985;67(3):416-9.

5. Maini PS, Sangwan SS, Sharma S, Chawla P, Kochar A. Rigid fixation of various fractures by tension band wiring. I J Orthop 1986;20:162-7.

6. Weber MJ, Janecki CJ, Mcleod P, Nelson CL, Thompson JA. Efficacy of various forms of fixation of transverse fractures of the patella. J Bone Joint Surg (Am) 1980;62:215-20.

7. El Nor TA, Issa KH. Minimally invasive tension band wiring for displaced transverse patellar fractures. The Egyptian Journal of Orthopaedics 2016;51(2):127-130. 